\title{
INTEGRASI PEMBELAJARAN GUIDED DISCOVERY DALAM MODUL SPERMATOPHYTA UNTUK MAHASISWA PENDIDIKAN BIOLOGI
}

\author{
Anwari Adi Nugroho ${ }^{*}$, Singgih Subiyantoro ${ }^{2}$ \\ ${ }^{1}$ Program Studi Pendidikan Biologi, Universitas Veteran Bangun Nusantara \\ Sukoharjo, Jalan Letjend Sujono Humardani No.1, Jombor, Bendosari, Sukoharjo \\ ${ }^{2}$ Program Studi Teknologi Pendidikan, Universitas Veteran Bangun Nusantara \\ Sukoharjo, Jalan Letjend Sujono Humardani No.1, Jombor, Bendosari, Sukoharjo, \\ *E-mail: bio_anwary@yahoo.com
}

\begin{abstract}
Guided discovery learning is a learning that invites students to actively discover the concept / knowledge through a series of activities. Guided discovery learning can be integrated in teaching modules to make learning more effective and self-reliant. This study aimed to integrate guided discovery learning in spermatophyta module for biology education students. This research is an explorative research with stages include curriculum analysis, subject matter analysis, learning model analysis, and integration of learning model in the Module. Data source in the form of book document, expert opinion, and spermatophyta module. Data analysis used qualitative descriptive analysis. Based on the analysis result, it is found that guided discovery guided discovery integrated in module include stimulation, problem statement, data collection, verification, generalization. The guided discovery guided synthesis is integrated into 3 subspaces on spermatophyta material 1) classification, determination, and nomenclature of plants, 2) spermatophyta (seed plants); 3) high plant herbarium. Integration of guided discovery learning on unified modules integrated in the module component of learning activities.

Keywords: Guided discovery, Spermatophyta Module
\end{abstract}

Pembelajaran biologi merupakan salah satu pembelajaran sains yang dalam pembelajarannya menekankan pada keterlibatan aktif (student centered learning) dan pemberian pengalaman langsung kepada mahasiswa dalam pembelajaran (Wenno, 2008). Pendidik dalam pembelajaran biologi berperan sebagai fasilitator dan menempatkan perhatian yang lebih banyak pada keterlibatan, inisiatif dan interaksi mahasiswa (McCombs \& Miller: 2007). Tujuan utama pembelajaran aktif (student centered learning) adalah menuntun mahasiswa mandiri dalam pembelajaran, pengembangan keterampilan berkomunikasi, pemahaman konsep materi, keterampilan pemecahan masalah (Jacobsen et al, 2009). Salah satu 


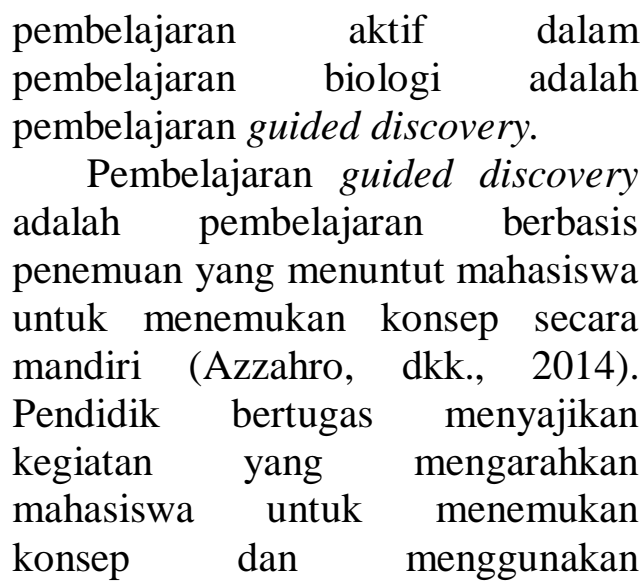
pengalamannya dalam mengerjakan tugas atau menjawab pertanyaan (Drost \& Todorovich, 2013). Pembelajaran guided discovery diawali dengan pemberian pertanyaan kepada mahasiswa. Pertanyaan-pertanyaan yang diajukan berkembang menjadi banyak pertanyaan yang lebih kompleks dan spesifik dengan tujuan mengarahkan mahasiswa ke kesimpulan yang diharapkan. Mahasiswa dapat melakukan percobaan untuk membuktikan pendapat /jawaban yang telah dikemukakan. Pembimbingan dalam pembelajaran guided discovery memberikan keuntungan untuk meningkatkan pemahaman konsep (Alfieri, Patricia, \& Naomi, 2011). Pembimbingan oleh dosen bertujuan untuk membantu mahasiswa dalam memahami tujuan dan prosedur kegiatan pembelajaran (Ratumanan, 2009).

Langkah-langkah pembelajaran guided discovery menurut Muhammad (2012) antara lain 1) stimulation berisi penyajian persoalan kepada mahasiswa atau meminta mahasiswa membaca atau mendengarkan uraian yang memuat persoalan. 2) problem statement, berisi kegiatan mahasiswa untuk

mengidentifikasikan berbagai permasalahan. 3) data collection, berisi kegiatan proses mengumpulkan data melalui literatur, mengamati objek, wawancara dengan nara sumber maupun melakukan uji coba sendiri. 4) data processing, berisi kegiatan menganalisis hasil pengumpulan data. 5) verification, berisi kegiatan pembuktian hasil pengolahan data dan informasi. 6) generalization, berisi kegiatan penyimpulan dari hasil pengamatan dan verifikasi yang telah dilakukan. Pembelajaran guided discovery sangat besar manfaatnya dalam proses pembelajaran. Kegiatan penemuan dalam pembelajaran discovery learning dapat meningkatkan hasil belajar kognitif (Nugroho, 2017), afektif, psikomotor dan kemampuan memecahkan masalah mahasiswa (Bambang \& Anwar, 2009; Nastiti, 2012; Purnomo, dkk., 2016). Pembelajaran guided discovery dapat diintegrasikan dalam modul ajar.

Modul merupakan paket belajar mandiri untuk membantu peserta didik mencapai tujuan belajar yang meliputi rangkaian pengalaman belajar yang direncanakan dan dirancang dengan sistematis (Mulyasa, 2006). Wena (2011) menjelaskan bahwa modul memiliki karakteristik tertentu yang membedakanya dengan bahan ajar lain, diantaranya adalah self contain, bersandar pada perbedaan individu, adanya asosiasi, pemakaian media yang bervariasi, partisipasi aktif oleh mahasiswa, penguatan langsung dan pengawasan strategi evaluasi. Integrasi pembelajaran guided discovery pada modul ajar dilakukan dengan menganalisis sintaks/tahapan 
pembelajaran dan materi pembelajaran. Integrasi pembelajaran guided discovery pada modul ajar secara khusus pada mata kuliah sistematika tumbuhan tinggi materi spermatophyta. Integrasi guided discovery pada modul ajar menghasilkan modul ajar Spermatophyta berbasis guided discovery. Manfaat pembelajaran dengan modul adalah memberikan pengaruh signifikan terhadap prestasi akademik mahasiswa (Acelajado, 2005). Pembelajaran dengan modul juga memberikan kepercayaan diri dan ketekunan mahasiswa sehingga aktivitas belajar mahasiswa meningkat (Rogers, 2004). Modul ajar digunakan oleh mahasiswa sebagai sumber belajar sehingga dapat mengarahkan mahasiswa untuk belajar secara mandiri. Penggunaan modul sebagai sumber belajar mahasiswa dapat memberikan kesempatan pada mahasiswa untuk mengembangkan kemampuan berpikirnya.

\section{METODE}

Penelitian ini merupakan penelitian eksploratif yang bertujuan untuk mengintegrasikan pembelajaran guided discovery dalam modul spermatophyta pada mata kuliah sistematika tumbuhan tinggi. Penelitian ini hanya sampai tahap integrasi dan tidak sampai pada tahap validasi produk. Data yang dibutuhkan dalam penelitian ini adalah tahapan/sintaks pembelajaran guided discovery, modul spermatophyta, dan materi spermatophyta. Sintaks guided discovery yang diintegrasikan antara lain stimulation, problem statement, data collection, data processing, verification, generalization (Muhammad, 2012). Sumber data berupa dokumen berupa buku, pendapat para ahli tentang pembelajaran guided discovery dan modul sistematika tumbuhan tinggi materi spermatophyta. Analisis data menggunakan analisis deskriptif kualitatif. Data berupa sintaks pembelajaran guided discovery dianalisis dan diintegrasikan pada modul sistematika tumbuhan tinggi materi spermatophyta. Berikut tahapan penelitian integrasi pembelajaran guided discovery dalam modul spermatophyta.

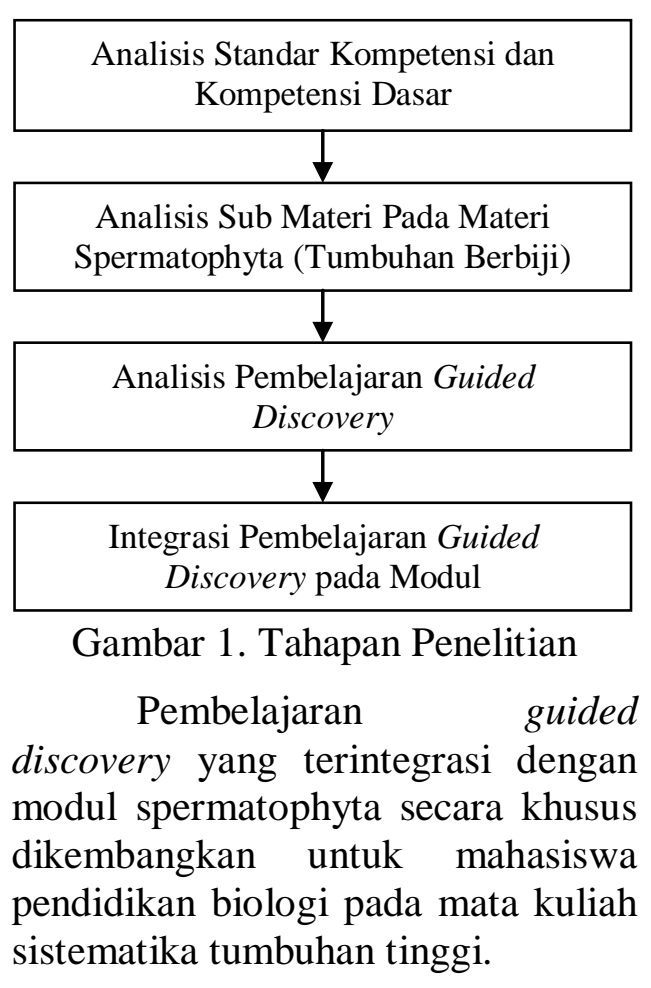

\section{HASIL DAN PEMBAHASAN}

Pembelajaran guided discovery merupakan pembelajaran aktif yang sesuai dengan karakteristik pembelajaran biologi. Pembelajaran guided discovery perlu diintegrasikan pada modul ajar untuk membantu mahasiswa mengembangkan aspek pengetahuan, 
keterampilan, dan sikap (Brigenta, dkk., 2017; Handoko, dkk., 2016).

\section{Analisis Standar Kompetensi dan Kompetensi Dasar}

Integrasi pembelajaran

guided discovery ke dalam modul spermatophyta didahului dengan menganalisis standar kompetensi dan kompetensi dasar yang ada pada modul spermatophyta. Standar kompetensi yang dipakai adalah mahasiswa mampu mengenali, mengidentifikasi, dan mengelompokkan jenis-jenis tumbuhan berdasarkan struktur kedudukan taksonominya mulai dari kingdom, divisi, kelas, ordo, famili, genus, dan spesies.

Sedangkan kompetensi dasar yang digunakan antara lain 1) mejelaskan sistem klasifikasi dan kunci determinasi tumbuhan, 2) memahami aturan tatanama tumbuhan tinggi, 3) menentukan ciriciri, klasifikasi, dan contoh tumbuhan gymnospermae, 4) menentukan ciri-ciri, klasifikasi, dan contoh tumbuhan angiospermae, 5) menjelaskan ciri-ciri, taksonomi dan sistematika tumbuhan monokotiledon dan dikotiledon, 6) menentukan ciri dan jenis tumbuhan dikotiledon sub kelas apetalae, 7) menentukan ciri dan jenis tumbuhan dikotiledon sub kelas dialypetalae, 8) menentukan ciri dan jenis tumbuhan dikotiledon sub kelas sympetalae, 9) mengidentifikasi dan mendeterminasi tumbuhan tinggi sekitar lingkungan kampus univet bantara Sukoharjo, 10) menentukan dan menjelaskan ciri khusus setiap famili pada tumbuhan spermatophyta yang terdapat pada lingkungan kampus univet bantara Sukoharjo,
11) membuat herbarium kering berdasarkan tumbuhan yang teridentifikasi di lingkungan kampus univet bantara Sukoharjo.

Analisis Sub Materi Pada Materi Spermatophyta (Tumbuhan Berbiji)

Materi spermatophyta pada modul spermatophyta (Tumbuhan Berbiji) terdiri dari: spermatophyta (tumbuhan berbiji) yang terdiri dari 3 bab/ sub materi antara lain 1) klasifikasi, determinasi, dan tatanama tumbuhan, 2) spermatophyta (tumbuhan berbiji), 3) herbarium tumbuhan tinggi.

\section{Analisis Pembelajaran Guided Discovery}

Pembelajaran yang dipilih untuk diintegrasikan dengan modul spermatophyta yaitu pembelajaran guided discovery. Pemilihan pembelajaran guided discovery untuk diintegrasikan pada modul karena pembelajaran guided discovery sesuai dengan karakteristik materi spermatophyta dan bersifat konstruktivis sehingga sehingga sesuai dengan pembelajaran biologi. Drost \& Todorovich (2013); Alfieri, Patricia, \& Naomi, 2011) menyatakan pembelajaran guided discovery menuntun mahasiswa untuk belajar menemukan konsep mandiri maupun kelompok. Langkah-langkah guided discovery meliputi stimulation (stimulasi), problem statement (pendapat tentang permasalahan), Data collection (pengumpulan data), Data processing (analisis data), Verification (verifikasi), Generalization (penyimpulan) (Muhammad, 2012).

Tahap simulation, dosen mengajukan persoalan atau meminta 
mahasiswa membaca atau mendengarkan uraian yang memuat persoalan. Persoalan/ permasalahan dapat meningkatkan antusias dan respon positif terhadap materi pembelajaran (Yuliani, Keliat, Sastrodihardjo, Kurniawati, 2017). Pemberian stimulus dapat membantu peserta didik dalam mengembangkan kemampuan bereksplorasi (Wahjudi, 2015). Tahap problem statement, mahasiswa diberi kesempatan mengidentifikasikan berbagai permasalahan.. Tahap data collection, proses mengumpulkan data dapat berupa membaca literatur, mengamati objek, wawancara dengan narasumber maupun melakukan percobaan. Pencarian informasi dengan percobaan dapat membuat peserta didik lebih memahami konsep (Balim, 2009).

Tahap data processing, data dan informasi yang didapatkan pada proses data coleccting diklasifikasi dan ditabulasi. Tahap verification, berdasarkan hasil pengolahan data dan informasi, pertanyaan pada tahap problem statement kemudian

Tabel 1. Matrik Integrasi Pembelajaran Guided Discovery Pada Modul

\begin{tabular}{lcl}
\hline \multicolumn{1}{c}{ Bab/sub materi } & $\begin{array}{c}\text { Kegiatan } \\
\text { Belajar }\end{array}$ & \multicolumn{1}{c}{$\begin{array}{c}\text { Tema Pembelajaran Guided } \\
\text { Discovery }\end{array}$} \\
\hline $\begin{array}{l}\text { Klasifikasi, Determinasi, dan } \\
\text { Tatanama Tumbuhan }\end{array}$ & 1 & $\begin{array}{l}\text { Pembuatan Kunci Determinasi } \\
\text { Buatan }\end{array}$ \\
$\begin{array}{l}\text { Spermatophyta (Tumbuhan } \\
\text { Berbiji) }\end{array}$ & 2 & $\begin{array}{l}\text { Perbedaan Angiospermae dengan } \\
\text { Gymnospermae } \\
\text { Perbedaan Dikotil dan Monokotil } \\
\end{array}$ \\
& 4 & $\begin{array}{l}\text { Identifikasi Tumbuhan dalam kelas } \\
\text { Monocotyledoneae } \\
\text { Identifikasi Tumbuhan dalam kelas } \\
\text { Dicotyledoneae } \\
\text { Identifikasi Tumbuhan dalam kelas } \\
\text { Dicotyledoneae } \\
\text { - }\end{array}$ \\
\hline
\end{tabular}

didiskusikan dengan kelompok dan dosen, serta mengkroscek jawaban apakah sudah terbukti benar. Sartika \& Lestari (2016) dalam penelitiannya menyatakan diskusi kelompok yang kooperatif dapat memberikan kesempatan pada peserta didik untuk mengekspresikan pemahaman materi yang dipelajari. Peran dosen dalam membimbing mahasiswa berdikusi dengan memberikan motivasi dapat menjadikan mahasiswa lebih tertarik dalam pembelajaran (Supriyanto, 2014). Tahap generalization, mahasiswa belajar menarik kesimpulan dan generalisasi dari hasil pengamatan dan verifikasi yang telah dilakukan.

\section{Integrasi Pembelajaran Guided Discovery pada Modul}

Modul spermatophyta terdiri 3 bab/sub materi, masing-masing terdiri dari komponen materi, kegiatan belajar dan rangkuman. Komponen kegiatan belajar diintegrasikan dengan pembelajaran guided discovery. 
Tabel 1 menunjukkan integrasi pembelajaran guided discovery dalam modul yang terbagi menjadi 6 kegiatan belajar. Masingmasing kegiatan pembelajaran berisi tahapan pembelajaran guided discovery meliputi stimulation, problem statement, data collection, data processing, verification, generalization.

Kegiatan belajar 1 bertema pembuatan kunci determinasi buatan diawali dengan stimulation. Stimulation berisi kegiatan observasi tanaman di sekitar lingkungan kampus kemudian mengambil tanaman sebanyak 4. Tahap selanjutnya adalah problem statement. Pada tahap problem statement, mahasiswa diminta untuk menuliskan rumusan masalah dan tujuan. Kegiatan dilanjutkan dengan data collecting yaitu pengamatan terhadap penampang ciri (kategori) yang mudah dilihat secara makroskopis dan bersifat tetap terhadap 4 tumbuhan, kemudian menuliskannya pada tabel pembanding. Pada tahap data prosessing mahasiswa diminta menyusun kunci determinasi (dikotomi) parallel kemudian memverifikasinya (tahap verification) dengan berdiskusi kelompok, mengkaji literatur, dan konfirmasi dengan dosen. Hasil kegiatan dipresentasikan (tahap generalitation) di depan kelas.

Kegiatan belajar 2 bertema perbedaan angiospermae dengan gymnospermae diawali kegiatan pengamatan (tahap stimulation) terhadap 3 tumbuhan yang telah dibawa (1 tumbuhan gymnospermae dan 2 tumbuhan angiospermae). Mahasiswa kemudian diminta menuliskan rumusan masalah dan tujuan (tahap problem statement). Pada tahap data collecting mahasiswa diminta melakukan identifikasi terhadap 3 tumbuhan tersebut. Identifikasi dilakukan terhadap perbedaan penampang ciri (kategori) yang mudah dilihat secara makroskopis.

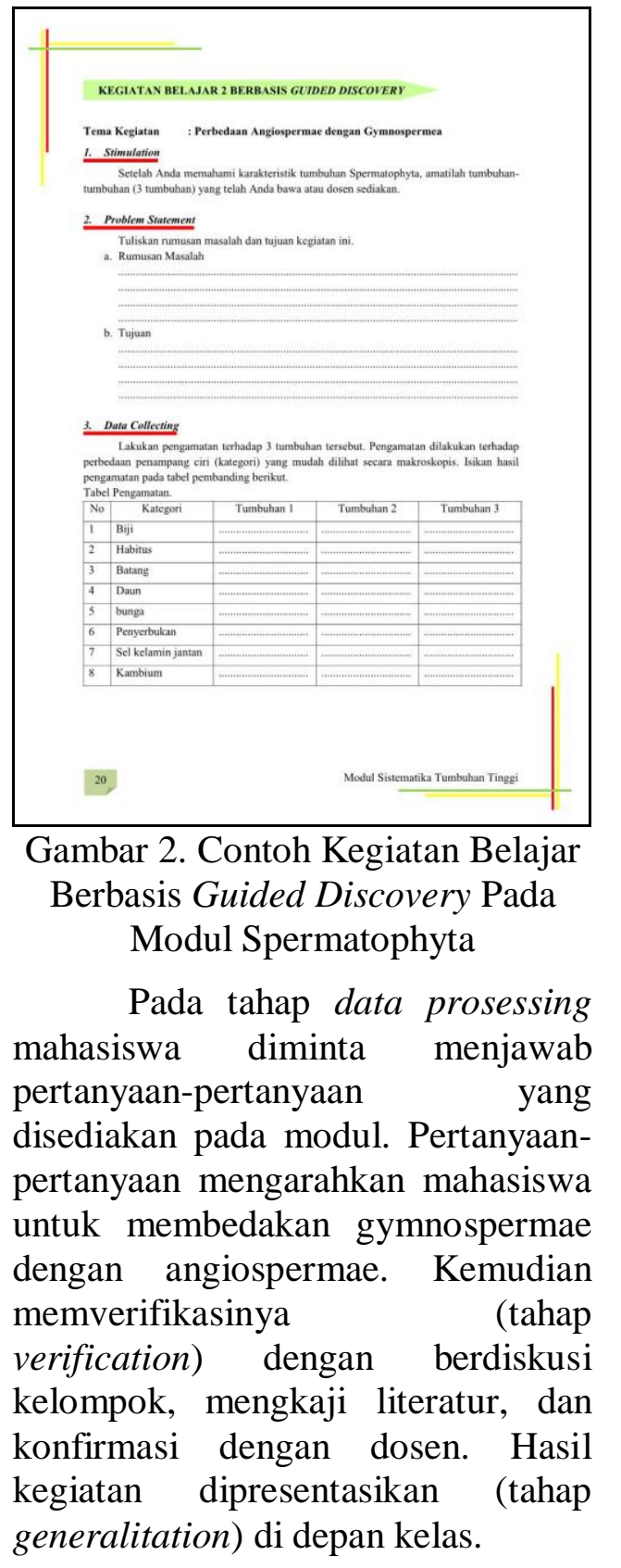




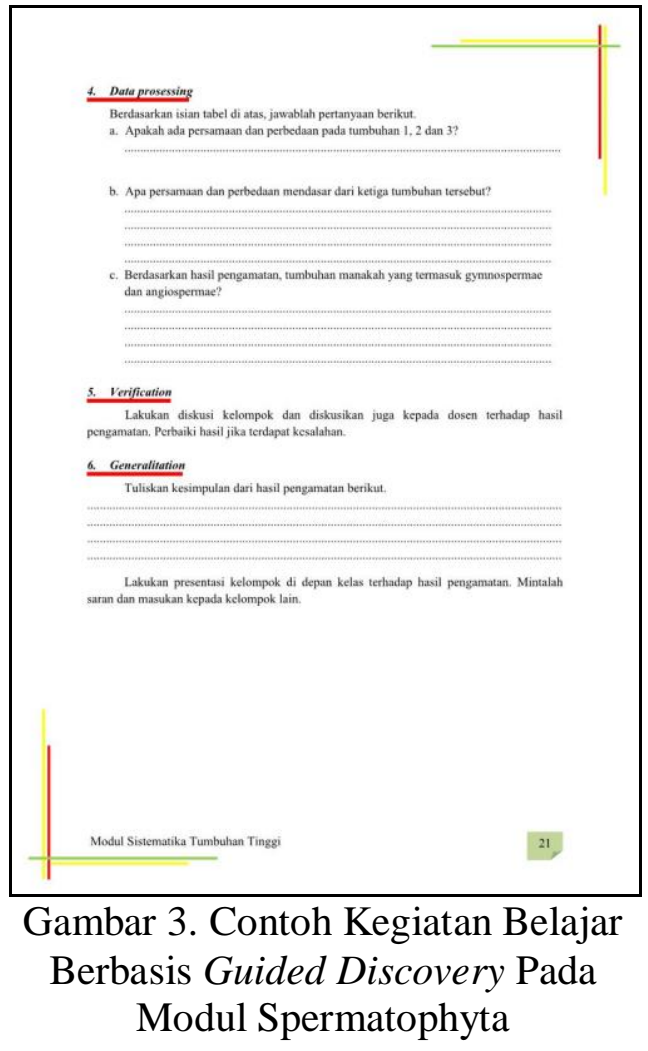

Kegiatan belajar 3 bertema perbedaan dikotil dengan monokotil, kegiatan diawali dengan pengamatan (tahap stimulation) terhadap 4 tumbuhan ( 2 tumbuhan dikotil dan 2 tumbuhan monokotil). Selanjutnya mahasiswa diminta menuliskan rumusan masalah dan tujuan (tahap problem statement). Tahap data collecting mahasiswa melakukan identifikasi terhadap 3 tumbuhan tersebut. Identifikasi dilakukan terhadap perbedaan penampang ciri (kategori) yang mudah dilihat secara makroskopis. Tahap data prosessing mahasiswa diminta menjawab pertanyaan-pertanyaan yang disediakan pada modul. Pertanyaanpertanyaan mengarahkan mahasiswa untuk membedakan dikotil dengan monokotil. memverifikasinya (tahap verification) dengan berdiskusi kelompok, mengkaji literatur, dan konfirmasi dengan dosen. Hasil kegiatan dipresentasikan (tahap generalitation) di depan kelas.

Kegiatan belajar 4 bertema identifikasi tumbuhan dalam kelas monocotyledoneae. Tahap stimulation berisi kegiatan pengamatan terhadap tanaman rumput, rumput teki, talas/ senthe, dan anggrek. Tahap problem statement berisi kegiatan mahasiswa menuliskan rumusan masalah dan tujuan. Tahap data collecting berisi kegiatan determinasi tumbuhan untuk menentukan klasifikasi tumbuhan meliputi takson kingdom, super divisi, divisi, kelas, ordo, famili, genus, dan spesies. Kegiatan determinasi tumbuhan, mahasiswa diarahkan menggunakan literatur berupa modul dan buku flora. Tahap data prosessing mahasiswa diminta menjawab pertanyaan-pertanyaan yang disediakan pada modul. Pertanyaan-pertanyaan lebih memfokuskan pada famili setiap spesies, ciri utama famili dan contoh spesies setiap famili. Tahap verification, mahasiswa berdiskusi kelompok, mengkaji literatur, dan konfirmasi kepada dosen hasil data prosessing. Hasil kegiatan dipresentasikan (tahap generalitation) di depan kelas.

Kegiatan belajar 5 bertema identifikasi tumbuhan dalam kelas dicotyledoneae. Kegiatan pertama (tahap stimulation) berisi kegiatan pengamatan tumbuhan-tumbuhan (6 tumbuhan). Tumbuhan yang diamati adalah tumbuhan bunga matahari, tanaman hias euphorbia, keningkir, kecubung/ tomat, cabai/ terong, patikan kebo, lengkap dengan anggota tubuhnya yaitu batang, akar, daun, dan bunga. Kegiatan selanjutnya (tahap problem statement 
) yaitu kegiatan mahasiswa menuliskan rumusan masalah dan tujuan. Tahap data collecting berisi kegiatan determinasi tumbuhan yang telah dibawa dan diamati untuk menentukan klasifikasi tumbuhan meliputi takson kingdom, super divisi, divisi, kelas, sub kelas, ordo, famili, genus, dan spesies. Kegiatan determinasi tumbuhan, mahasiswa diarahkan menggunakan literatur berupa modul dan buku flora. Tahap data prosessing mahasiswa diminta menjawab pertanyaan-pertanyaan yang disediakan pada modul. Pertanyaan-pertanyaan lebih memfokuskan pada famili setiap spesies, ciri utama famili dan contoh spesies setiap famili. Tahap verification, mahasiswa berdiskusi kelompok, mengkaji literatur, dan konfirmasi kepada dosen hasil data prosessing. Hasil kegiatan dipresentasikan (tahap generalitation) di depan kelas.

Kegiatan belajar 6 bertema identifikasi tumbuhan dalam kelas dicotyledoneae. Kegiatan pertama yaitu tahap stimulation berisi kegiatan pengamatan tumbuhantumbuhan (6 tumbuhan). Tumbuhan yang diamati adalah tumbuhan bunga matahari, tanaman hias euphorbia, keningkir, kecubung/ tomat, cabai/ terong, patikan kebo, lengkap dengan anggota tubuhnya yaitu batang, akar, daun, dan bunga. Selanjutnya tahap problem statement yaitu kegiatan mahasiswa menuliskan rumusan masalah dan tujuan. Tahap data collecting berisi kegiatan determinasi tumbuhan yang telah dibawa dan diamati untuk menentukan klasifikasi tumbuhan meliputi takson kingdom, super divisi, divisi, kelas, sub kelas, ordo, famili, genus, dan spesies.
Kegiatan determinasi tumbuhan, mahasiswa diarahkan menggunakan literatur berupa modul dan buku flora. Tahap data prosessing mahasiswa diminta menjawab pertanyaan-pertanyaan yang disediakan pada modul. Pertanyaanpertanyaan lebih memfokuskan pada famili setiap spesies, ciri utama famili dan contoh spesies setiap famili. Tahap verification, mahasiswa berdiskusi kelompok, mengkaji literatur, dan konfirmasi kepada dosen hasil data prosessing. Hasil kegiatan dipresentasikan (tahap generalitation) di depan kelas.

Hasil integrasi berupa modul spermatophyta berbasis guided discovery. Kegiatan guided discovery dalam modul mampu membuat peserta didik untuk berdiskusi aktif dalam kelompok mengembangkan berpikir kritis dan memahami konsep dari suatu materi (Agustina, dkk., 2015). Selain itu pembelajaran guided discovery menuntun mahasiswa untuk mencari jawaban/ memecahkan masalah sehingga membuat rasa ingin tahu meningkat (Widiadnyana, dkk., 2014).

Modul ajar berbasis model pembelajaran membuat pembelajaran lebih efektif dalam memberdayakan kemampuan berpikir (Rohmiyati, dkk., 2016; Yuliani, dkk., 2017). Handoko, dkk. (2016) dalam penelitiannya menjelaskan bahwa modul biologi berbasis guided discovery efektif memberdayakan hasil belajar dari aspek sosial, aspek keterampilan dan aspek pengetahuan. Sementara penelitian dari Septianu, dkk. (2014) menjelaskan bahwa implementasi modul berbasis discovery efektif memberdayakan hasil belajar peserta didik. 


\section{SIMPULAN DAN SARAN}

Berdasarkan hasil penelitian disimpulkan bahwa sintak pembelajaran guided discovery yang diintegrasikan dalam komponen kegiatan belajar pada modul meliputi stimulation, problem statement, data collection, data processing, verification, dan generalization. Sintak pembelajaran guided discovery diintegrasikan pada 3 sub materi pada materi spermatophyta yaitu 1) klasifikasi, determinasi, dan tatanama tumbuhan, spermatophyta (tumbuhan berbiji); 3) herbarium tumbuhan tinggi.

Saran dari penelitian ini adalah pembelajaran guided discovery yang diinterassikan pada modul dapat dikembangkan lagi secara khusus untuk memberdayakan kemampuan berpikir tingkat tinggi dan dapat juga dikembangkan pada bahan ajar mata kuliah lain.

\section{UCAPAN TERIMAKASIH}

Peneliti mengucapkan terimakasih kepada DRPM Dikti (Kemenristekdikti) yang telah mendanai penelitian dosen pemula ini Tahun 2017 dan Universitas Veteran Bangun Nusantara Sukoharjo selaku institusi penulis bernaung yang telah mendukung penuh pelaksanaan penelitian ini.

\section{DAFTAR PUSTAKA}

Acelajado, M. J. (2005). The Modular Teaching Approach in College Algebra : An Alternative to Improving the Learner's Achievement, Persistence, and Confidence in Mathematics. International Journal of Education and
Development, Vol 5, No 6, (294-312).

Agustina, M., Arwin, A., \& Berti, Y. (2015). Pengaruh Model Discovery learning terhadap Kemampuan Berpikir Kritis dan Hasil Belajar Siswa. Jurnal Bioterdidik, Vol. 3, No.6.

Alfieri, Patricia, \& Naomi. (2011). Does Discoverybased Instruction Enhance Learning. Journal of Education Psychological, Vol. 103, No.1, 1-18.

Azzahro, I., Raharjo., \& Elok, S. (2014). Pengembangan Perangkat Pembelajaran Berbasis Discovery learning Pada Sub Materi Respirasi Dan Fotosintesis Kelas VII SMP. Jurnal Pendidikan Sains UNESA, Vol. 2, No.03.

Balim, A.G. (2009). The Effects of Discovery learning On Students' Success and Inquiry Learning Skills. Eurasian Journal of Educational Research, Issue 35, spring 2009, I2.

Bambang S. \& Anwar S. (2009). Pengembangan Model Pembelajaran Discovery Learning Ilmu Pendidikan untuk Meningkatkan Pemahaman Konsep Pendidikan Mahasiswa PGSD FIP UNY. Jurnal Penelitian Ilmu Pendidikan, Vol. 2, No. 1, 54 . 
Brigenta, D., Handhika, J., Sasono, M. (2017). Pengembangan modul berbasis discovery learning untuk meningkatkan pemahaman konsep. Prosiding Seminar Nasional Pendidikan Fisika III 2017 "Etnosains dan Peranannya Dalam Menguatkan Karakter Bangsa". (pp. 167-173). Universitas PGRI Madiun

Drost \& Todorovich. (2013). Enhancing Cognitive Understanding to Improve Fundamental Movement Skills. Journal of Physical Education, Recreation, and Dance, 84, 54-59.

Handoko, A., Sajidan., Maridi. (2016). Pengembangan Modul Biologi Berbasis Discovery Learning (Part Of Inquiry Spectrum LearningWenning) Pada Materi Bioteknologi Kelas Xii IPA di SMA Negeri 1 Magelang Tahun Ajaran 2014/2015. Jurnal Inkuiri, Vol. 5, No.3, 144-154.

Jacobsen, D. A., Eggen, P., \& Kauchak, D. (2009). Methods for Teaching Metode-metode Pengajaran Meningkatkan Belajar Peserta Didik TKSMA. Yogyakarta: Pustaka Pelajar.

McCombs, B., \& Miller, L. (2007). Learner-centered classroom practices and assessments. Thousand Oaks, CA: Corwin Press.
Muhammad, T. I. (2012). Pembelajaran Discovery Strategi \& Mental Vacational skill. Yogyakarta : Diva Press.

Mulyasa, E. (2006). Kurikulum Berbasis Kompetensi. Bandung :Rosda Karya.

Nastiti, S., Antonius,. \& Woro, S. (2012). Efektifitas Model Pembelajaran Guided Discovery Learning terhadap Kemampuan Memecahkan Masalah Kimia. Chemistry in Education, Vol. 2, No.1, 4955.

Nugroho, A. A. (2017). The implementation of collaborative-based guided discovery reviewed from students' analytical thinking skills and social skills. Jurnal Inovasi Pendidikan IPA, Vol. 3, No.2, 128-136. doi:http://dx.doi.org/10.2183 1/jipi.v3i2.14508

Purnomo, H.Y., Mujasam, \& Yusuf, I. (2016). Penerapan Model Guided Discovery Learning Pada Materi Kalor Terhadap Hasil Belajar Kognitif Peserta Didik Kelas VII SMPN 13 Prafi Manokwari Papua Barat. Jurnal Pancaran Pendidikan. Vol. 5, No. 2.

Ratumanan. (2009). Model-model Pembelajaran. Jakarta Bumi: Aksara.

Roger, M. E. (2004). A Comparison of the Effectiveness of Modular Drafting Instruction 


$\begin{array}{lr}\text { versus } & \text { Contemporary } \\ \text { Drafting } & \text { Instruction on } \\ \text { Collegiate } & \text { Technology } \\ \text { Education } & \text { Students. } \\ \text { International } & \text { Journal of } \\ \text { Industrial Teacher Education } \\ \text { Vol.41, No. 2, 37-90. }\end{array}$

Rohmiyati, N., Ashadi, A., \& Utomo, S. (2016). Pengembangan modul kimia berbasis inkuiri terbimbing pada materi reaksi oksidasi - reduksi. Jurnal Inovasi Pendidikan IPA, Vol. 2, No. 2 , 223-229. doi:http://dx.doi.org/10.2183 1/jipi.v2i2.4869

Sartika, R.P., \& Lestari, I. (2016). Peningkatan Pemahaman Siswa Pada Materi Koloid Menggunakan Pembelajaran Model. Jurnal Pendidikan Matematika dan IPA, Vol. 7 No. 2, 32-43.

Septianu, E., Sudarmin, \& Widiyatmoko, A., (2014). Pengembangan Modul IPA Terpadu Tema Perubahan Zat Berbasis Discovery Untuk Meningkatkan Keterampilan Generik dan Hasil Belajar Siswa. Unnes Science Education Journal. Vol. 3, No. 3, 653-661.

Supriyanto, B. (2014). Penerapan Discovery learning untuk Meningkatkan Hasil Belajar Siswa Kelas VI B Mata Pelajaran Matematika Pokok Bahasan Keliling dan Luas Lingkaran di SDN Tanggul Wetan 02 Kecamatan Tanggul Kabupaten Jember.
Jurnal Pancaran Pendidikan FKIP UNEJ.

Wahjudi, E. (2015). Penerapan Discovery learning dalam Pembelajaran IPA sebagai Upaya untuk Meningkatkan Hasil Belajar Siswa Kelas IXI di SMP Negeri 1 Kalianget . Jurnal Lensa, Vol.5, No.1.

Widiadnyana, I. W., Sadia, I. W., \& Suastra, I.W. (2014). Pengaruh Model Discovery learning Terhadap Pemahaman Konsep IPA dan Sikap Ilmiah Siswa SMP. Jurnal Pascsarjana Universitas Pendidikan Ganesha Progam Studi IPA, Vol. 4.

Wena, M. (2011). Strategi Pembelajaran Inovatif Komteporer. Jakarta : PT. Bumi Aksara.Jakarta.

Wenno. (2008). Strategi Belajar Mengajar Sains Berbasis Kontekstual. Yogyakarta: Inti Media.

Yuliani, M., Keliat, N. R., Sastrodihardjo, S., \& Kurniawati, D. (2017). Pembelajaran Model Discovery Learning dan Strategi Bowling Kampus untuk Meningkatkan Hasil Belajar Kognitif dan Motivasi Belajar IPA. Jurnal Bioedukasi, Vol. 10, No. 1, 23-32. 